Dokuz Eylül Üniversitesi-Mühendislik Fakültesi Fen ve Mühendislik Dergisi Cilt 19, Sayı 57, Eylül 2017
Dokuz Eylul University-Faculty of Engineering Journal of Science and Engineering Volume 19, Issue 57, September 2017

DOI: $10.21205 /$ deufmd.2017195776

\title{
Olfaktometrik Yöntem ile Atıksu Arıtma Tesisi Ünitelerinde Koku Düzeylerinin Belirlenmesi
}

\author{
Kadir ULUTAŞ¹, Hakan PEKEY¹, Selami DEMİR², Faruk DİNÇER ${ }^{3}$ \\ ${ }^{1}$ Kocaeli Üniversitesi, Mühendislik Fakültesi, Çevre Mühendisliği Bölümü, 41380, Kocaeli \\ ${ }^{2}$ Yıldız Teknik Üniversitesi, İnşaat Fakültesi, Çevre Mühendisliği Bölümü, 34220, İstanbul \\ 3 TÜBİTAK MAM Çevre ve Temiz Üretim Enstitüsü, 41400, Kocaeli
}

(Alınış / Received: 27.01.2017, Kabul / Accepted: 15.05.2017, Online Yayınlanma/ Published Online: 20.09.2017)

Anahtar Kelimeler Olfaktometre 1, Koku Kirliliği 2, Atıksu Arıtma Tesisleri 3

Özet: Atıksu arıtma tesisleri faaliyetleri gereği koku kaynağı olarak bilinir ve genellikle şikayete konu olur. Çünkü koku uzun dönemde ve yüksek yoğunlukta insan davranışlarını ve çevreyi olumsuz etkiler. Bu çalışmanın amacl tesisin ünitelerinde koku konsantrasyonlarının belirlenmesidir. Bu nedenle 11 ayrı ünitede 3 farklı dönemde olfaktometrik yöntem ile koku ölçümleri yapılmıştır. Tesiste en yüksek koku oluşumu sırasıyla çamur kurutma (\%39), çamur yoğunlaştırma (\%9), anaerobik havuz (\%9), ön çöktürme (\%8), son çöktürme (\%8), ince izgara (\%7), kum tutma (\%7), setrant (\%7) ve giriş-kaba Izgara (\%6) ünitelerinde tespit edilmiştir. Ayrıca koku önleme sisteminin verimi (ozon) \%84,9, (UV) \%28,2 tespit edilmiştir.

Etkili bir koku kontrol sistemi ile atmosfere salınan emisyon değerlerinin yönetmelikte belirtilen idari yaptırım limitinin altına indirildiği görülmüştür. Bu sonuçlar tesiste etkili bir koku kontrol prosesinin gerçekleștiğini göstermektedir.

\section{Determination of Odor Levels in Wastewater Treatment Plants by Olfactometric Method}

\section{Keywords}

Olfactometry 1 , Odor Pollution2, Wastewater Treatment Plant 3

\begin{abstract}
Wastewater treatment plants are known as an odor source due to their activities and they cause complaints due to the fact that long term exposure to high concentrations of odors affects human behaviors and environment. The aim of this study is to detect the odor concentrations in the units of the facility. Thus, odor measurements were taken at 11 units of facility in three seasons. The rates of odor formation were, in order, found as sludge dewatering (39\%), sludge thickening (9\%), anaerobic tank (9\%), primary sedimentation (8\%), final sedimentation $(8 \%)$, fine screen $(7 \%)$, setrant $(7 \%)$ and inlet-coarse screen $(6 \%)$ units. Besides, the efficiencies of odor removal processes were found as $84.9 \%$ (Ozone) $28.2 \%$ (UV). With an effective odor control system, it has been found that the emissions are reduced below the legal limits. The results showed that odor control process is satisfactorily efficient.
\end{abstract}

*Sorumlu yazar: ulutaskadir1@gmail.com 


\section{Giriş}

Atıksu arıtma tesisleri genellikle çevresinde oturanlar tarafindan kötü kokuların kaynağı olarak bilinmekte olup [1], [2] meydana geldiği bölgeye zarar verir [3] ve ciddi sıkıntılar meydana getirir [4]. Bu nedenle aritma tesisleri meskûn alanda kokuya maruz kalan halkın olumsuz reaksiyon sergilemesine ve şikâyetlerine neden olur [5], [6], [7]. İnsan duyularının algılama özelliğine bağlı bir kirlenme türü olan koku [8] çevresel bir sorun olarak değerlendirilmektedir [9]. Koku, çevreyi algılamada kullandığımız en önemli duyularımızdan biridir. Koku algısı kișiden kișiye farklılık göstermekle birlikte kokudan olumsuz yönde etkilenmede kokunun konsantrasyonu, frekansı, süresi, hedonik tonu ve yoğunluğu gibi parametreler etkili olur [10]. Bu doğrultuda değerlendirildiğinde koku; "insanda koku alma duyusunu harekete geçiren ve kokunun algılanmasına neden olan uçucu maddelerin yarattığı etki" olarak tanımlanır [11].

Her ünitesinde ayrı bir arıtma prosesinin bulunduğu birbirine bağlı kompleks bir teknolojik sistem olan [5] atıksu arıtma tesisleri evsel ve endüstriyel atıksuları alıcı ortama deşarj etmeden önce fiziksel, kimyasal ve biyolojik olarak etkin bir şekilde arıtmak [12] için tasarlanmış bir dizi işlem ve süreçlerin bir arada yer aldığı mühendislik tesisleridir. Atıksu arıtma tesislerinin amacl atıksudaki kirleticileri giderirken çevresinde ikamet edenleri, halk sağlığını ve alıcı su ortamlarını korumaktır [6].

Arıtma proseslerinde en çok koku ham atıksuyun girdiği arıtma tesislerinin giriș, lzgara ve çamur ünitelerinde görülür [13], [14]. Genellikle koku oluşumu, atıksuyun taşınması ve arıtılması esnasında anaerobik ortamda organik maddelerin mikroorganizmalar tarafından parçalanmasıyla gerçekleşir
[15], [16]. Ön çöktürme tankında, çamur yoğunlaştırma ve diğer çamur arıtma ünitelerinde anaerobik çürütme prosesinden gelen çamur yüksek konsantrasyonda (özellikle indirgenmiş sülfür) kokulu bileşik içerir [17]. Atıksu aritma tesislerinde kokuya neden olan bileşiklerin bașında inorganik yapıda hidrojensülfür ve amonyak organik yapıda ise alkol, uçucu yağ asidi, aldehit, keton, tiyoeter ve merkaptanlar gibi azotlu ve kükürtlü bileşikler gelir [18]. Ayrica hayvan atıklar ve sıcak baharatların çürümesi amin, indol ve skatol gibi bileşiklerin oluşumuna katkı sağlar [16], [19], [20]. Bunların yanında sanayi atıksularının arıtıldı̆̆ arıtma tesislerinde bu sanayi türlerine bağlı olarak atıksular hem kokulu bileşikleri hem de arıtma prosesi esnasında koku üreten bileşikler gibi farklı koku türlerini de içerebilir [16], [21].

Havada çözünmüş halde çok düşük konsantrasyonlarda bulunan ve koku alma duyusuyla hissedilebilen kimyasal maddeden kaynaklı koku hem insanlarda oluşturduğu rahatsızlık [4] ve hem de bünyesinde barındırdığı kirleticilerin sebep olduğu çevresel etkilerden [9] dolayı günümüzde önem kazanmıștır [22]. Koku doğrudan bir hastalığa neden olmamasına rağmen, uzun vadede yüksek yoğunlukta kokuya maruz kalan insanların davranışlarında olumsuz etkileri olmasından ötürü istenmeyen koku emisyonlarını kontrol altına almak, azaltmak ve ortadan kaldırmak dünya çapında atıksu arıtma tesisleri için en önemli sorunlar arasında yer almıştır [12], [23].

Uzun süre kötü kokuya maruz kalarak kendini kötü hissetmeye başlayan kişide solunum ve sindirim problemleri, göz, burun ve boğaz tahriși, mide bulantısı, kusma, baş ağrısı ve depresyon gibi olumsuzluklar görülebilir. Bunların yanında koku kirliliğinin doğal çevre kalitesinin bozulması, mülkiyetin normal 
kullanımındaki beğenisinin kaybolması, iştah azalması, gece uyku konforunun azalması, ziyaretçilerin kokuya maruz kalmasından duyulan mahcubiyet, evi ve çamaşırları kokunun sarması, pencerelerin kapalı tutulmasından dolayı konforun azalması ve açık hava aktivitelerinden kaçınma gibi olumsuz etkileri de bulunmaktadır [12], [24], [25], [26]. Kısaca kokunun meydana getirdiği çevre kirliliği, bașta insanlar olmak üzere tüm ekolojik sistemi, ekonomiyi ve sosyal yaşamı olumsuz yönde etkileyebilir [1], [9].

Doğrudan veya dolaylı olarak insan faaliyetlerinden kaynaklanan ve olumsuz etkilere neden olan kokuların yaşam kalitesi ve sağllk ile ilişkisi tartışılmakla birlikte [5], [27], [28] bunlar kirletici olarak sınıflandırılmakta ve yasal düzenlemeye tabi tutulmaktadır. Türkiye'de koku sorunun çözümü noktasinda yasal sorumluluğun belirsizliği, yasal limitlerin olmayıșı ve koku problemine neden olanlara herhangi bir yaptırımın uygulanamaması gibi [29] problemlerin çözümü amacıyla ve ülkemizin Avrupa Birliği'ne tam üyeliğe aday olması nedeniyle yasal adaptasyon sürecinde koku kirliliği ile ilgili yönetmelik hazırlamak üzere 2002 yllında çalışmalara başlanmıştır [30]. Ülkemizde $\quad 04.09 .2010$ tarihinde yürürlüğe giren ilk yönetmelikte 19.07.2013 tarihinde değişiklik yapılarak Koku Oluşturan Emisyonların Kontrolü Hakkında Yönetmelik (KOEKHY) hükümleri uygulanmaya başlanmıştır.

Bir atıksu arıtma tesisinde koku konsantrasyonunun belirlenmesi yasal limit değerler içinde faaliyetin yürütülmesi, koku algısının değerlendirilmesi, tesiste kullanılan koku giderim ünitesinin verimliliğinin belirlenmesi ve koku kaynağı olmadığının tespiti açısından önemlidir.
$\mathrm{Bu}$ çalışmada, bölgesinde en yüksek kapasiteye sahip ve geçmişte şikayetlere konu olmuş bir atısu arıtma tesisinde olfaktometrik metot ile EN 13725 ve KOEKHY hükümlerine göre koku konsantrasyonları tespit edilmiștir. $\mathrm{Bu}$ kapsamda tesisin 11 noktasında ölçüm yapılarak hem kendi içinde hem de tüm tesis göz önünde bulundurularak koku konsantrasyonları değerlendirilmiştir. Ayrıca bunun yanında tesis çalışanlarının koku algısı değerlendirilerek tesisin koku oluşum oranları karşılaştırılmıştır.

\section{Materyal ve Metot}

\subsection{Atıksu Arıtma Tesisi}

Çalıșma kapsamında ülkemizdeki büyük atıksu arıtma tesislerinden $\quad(250.000$ $\mathrm{m}^{3} /$ gün kapasiteli) biri seçilmiştir. Karbon, azot, fosfor giderimi ile biyolojik olarak atıksuların arıtıldığı tesiste enerji üretimi için kullanılan kojenerasyon sistemi sayesinde doğalgaz ile gaz türbininde tesisin elektrik ihtiyacı karşılanmaktadır.

Arıtma çamuru tesiste oluşan atık egzoz ısısı ile ilave enerji gerekmeksizin kurutulmakta ve faydalı ürüne dönüştürülmektedir. Böylece tesiste oluşan termal çamur kurutularak ek yakıt olarak değerlendirilmektedir. Ayrica tesiste kurulu bulunan çamur çürütme tankları ile tesis bünyesinde biyogaz üretilmektedir. Tesiste oluşan koku emisyonları ozon, UV ve biyodamlatmalı filtre ile arıtılmaktadır.

$140.000 \mathrm{~m}^{3} /$ saat kapasiteye sahip ana emiș fanı ile Şekil 2'de gösterilen ünitelerden toplanan kirli hava koku giderim ünitesinde yıkama kulesine girer. Atmosferden alınarak nemi giderilen hava yüksek basınç ile ozon jeneratörü sayesinde ozona dönüștürülür. Temiz su ile karıștırılan ozon kirli havaya püskürtülür ve kirli hava böylece yıkanır. Temiz hava ozon ünitesinin bacasından dışarı verilir. Havayı temizlemek için kullanılan su da 
kirlendiği için tesisin giriş ünitesine verilerek süreç devam eder. Şekil 1'de koku giderim ünitesinde kurulu bulunan ters akışlı scrubber sistemi gösterilmektedir.

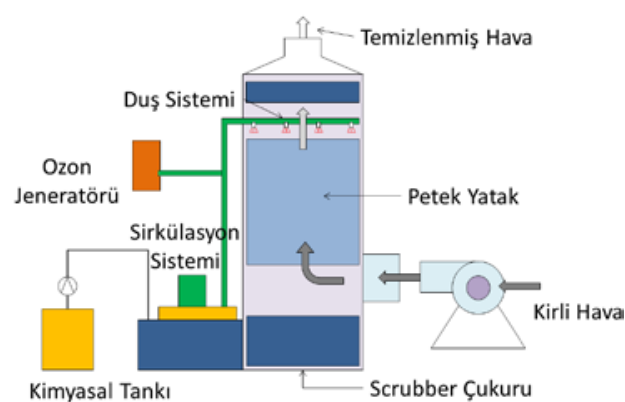

Şekil 1. Koku giderim ünitesi Ters Akışlı Scrubber Sistemi

\section{2. Örnek Alma Programı}

Atıksu arıtma tesisine ulaşan atıksuların kendine özel uygun teknoloji ile tespit edilebilen fiziksel, kimyasal ve biyolojik özellikleri vardır ve tesisin her ünitesinde ayrı bir proses uygulanarak arıtma işlemi gerçekleştirilmektedir. $\mathrm{Bu}$ nedenle aritma tesisinin her ünitesinde üretilen koku konsantrasyonunu belirlemek için tesiste toplam 11 noktadan 3 farklı tarihlerde (Kasım 2015, Mayıs 2016 ve Ağustos 2016) örnekleme yapılarak her noktadan 3'er örnek (toplam 99 örnek) alınmıștır. Tesis içinde giriş yapısı ve kaba ızgara (terfi merkezi), ince ızgaralar, havalandırmalı kum tutucular, ön çöktürme havuzları, anaerobik havuzlar, son çöktürme havuzları, çamur yoğunlaştırma ünitesi, çamur kurutma ünitesi, ozon (koku giderim) ünitesi, setrant giriş, setrant çıkış noktalarından örnekler alınmıştır.

Daha önce atıksu arıtma tesislerinde olfaktometrik yöntemlerin uygulandı̆̆ Dinçer tarafindan yapılan çalışmalar [31] da dikkate alınarak gaz halde hava örneği boru üzerindeki örnek alma deliği kullanılarak havuzlardan alınan örnekler ise üzeri kapalı davlumbaz kullanılarak 5 litrelik Nalophan torbalara pompa yardımıyla çekilmek suretiyle alınmıştır. Tek kullanımlık olan torbalar organik madde ve suya karşı geçirimsiz olup kokusuzdur. Örnekleme ve ölçüm esnasında kullanılan hortumlar PTFE (polytetrafluoroethylene) malzemeden yapılmıştır.

Yaptı̆̆ımız çalışma ile atıksudan kaynaklanan ve tesisin her bir ünitesinde meydana gelen kokunun konsantrasyonu olfaktometrik metot ile EN 13725 ve KOEKHY hükümlerine göre belirlenmiş olup Şekil 2'de tesis ünitelerinde örnek alma noktalarını gösterilmiştir.

\subsection{Koku Örneklerinin Analizi}

Toplanan örneklerin analizleri olfaktometre ile yapılmıştır. Olfaktometrik analizler EN 13725 ve KOEKHY'de belirtilen șartlara göre 30 saat içinde (Scentroid marka) olfaktometre ile gerçekleştirilmiştir. Kokusuz ve temiz bir laboratuvar ortamında olfaktometrenin Evet/Hayır metodu kullanılarak ilgili yönetmeliklere göre analizler yapılmıştır.
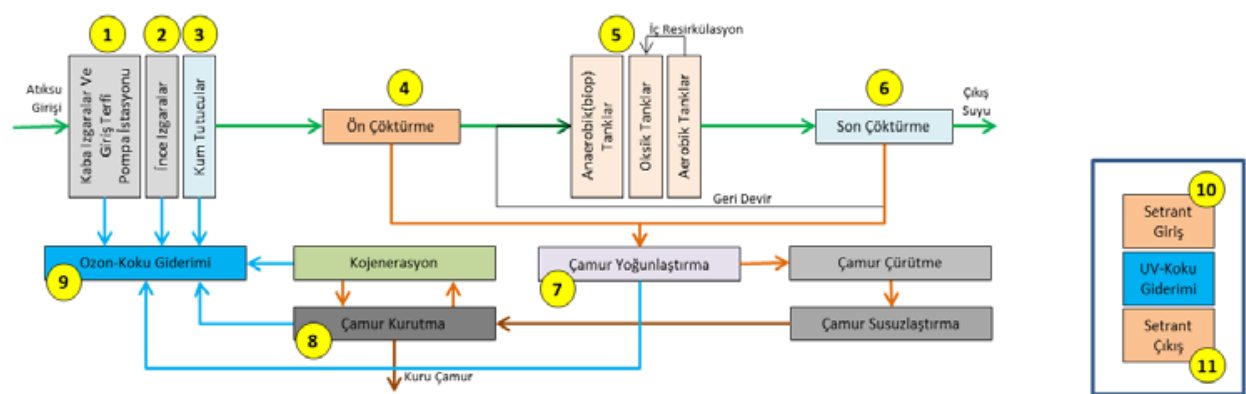

Şekil 2. Tesis ünitelerinde örnek alma noktaları 
Evet/Hayır metodu olfaktometride kullanılan paneliste "Koku var mı?" diye sorulan soruya "Evet" ya da "Hayır" yanitı alınan metottur [11]. Evet/Hayır metodunda panelistler kokulu havayı koklar. Daha sonra nötral hava ile kokulu havayı mukayese eder. Soludukları hava eğer kokulu ise "evet" değil ise "hayır" butonuna basarak örnek değerlendirmesi yapilır. Olfaktometrik ölçüm konusunda eğitilmiş ve istenilen niteliklere uygun 6 panelistin $\% 50$ 'si tarafindan kokunun hissedildiği konsantrasyon değeri olan gazın koku eşik değerine kadar nötral hava ile seyreltilmesi neticesinde örneğin koku konsantrasyonu belirlenmiş olur. Birimi Koku Birimi $/ \mathrm{m}^{3}$ tür $\left(\mathrm{KB} / \mathrm{m}^{3}\right)$. Bu işlemde görev alacak olan 1 panel lideri ve 6 panelist EN 13725 tarafından belirlenen niteliklere haiz olarak seçilmiştir. Olfaktometrik analiz sonuçları bilgisayarlı sistem tarafından otomatik olarak belirlenmektedir.

\subsection{Anket}

Teknik ölçüm ve uygulamaların yanında anket yöntemi ile kokuya maruz kalan kişilerin algısının değerlendirilmesi koku yönetimi açısından ayrı bir öneme sahiptir. Atıksu arıtma tesisi çevresinde görülen olumsuzluklar meskûn bölgede yaşayanlar kadar tesis çalışanlarını da etkiler [32]. $\mathrm{Bu}$ nedenle koku konsantrasyonunun değerlendirildiği çalışmamızda yaşamlarının önemli bir bölümünü tesiste geçiren çalışanların görüşleri anket uygulaması ile değerlendirmeye alınmıştır. Bu anketin düzenlenmesinde Frechen tarafından Almanya'da atıksu arıtma tesisinde çalışanların katıldığı ve tesisteki ünitelerin kokuya katkılarının belirlendiği anket çalışmasından [33] yararlanılmıștır.

Çalışmanın bu kısımda, tesis içinde çalışan personelin koku algısını ve tesis ünitelerinin koku kirliliğine katkısını değerlendirmek için tesis içinde bir anket çalışması yapılarak tesisin hangi ünitesinde kokunun daha fazla hissedildiği belirlenmeye çalışılmıştır. Böylece tesis içinde yapılan ölçümler ile çalışanlara yönelik yapılan anket sonuçları arasında bir ilișkinin olup olmadığı değerlendirilmiştir. Anket çalışmasına toplam 51 kişi katılmış olup bunlardan 40 kişinin anketi değerlendirmeye alınmıştır. Anket 5 adeti demografik yapı, 2 adeti tesis ünitelerindeki koku oluşumu ve 1 adeti koku oluşum zamanı ile ilgili olmak üzere toplam 8 sorudan oluşmuştur. Ankette en çok koku oluşumunun gözlemlendiği ünitelerin (1 en çok olanı göstermek üzere 2 ve 3 olarak) siralanması istenmiştir. Böylece koku algısı ile ünitelerin değerlendirilmesi yapılmıștır.

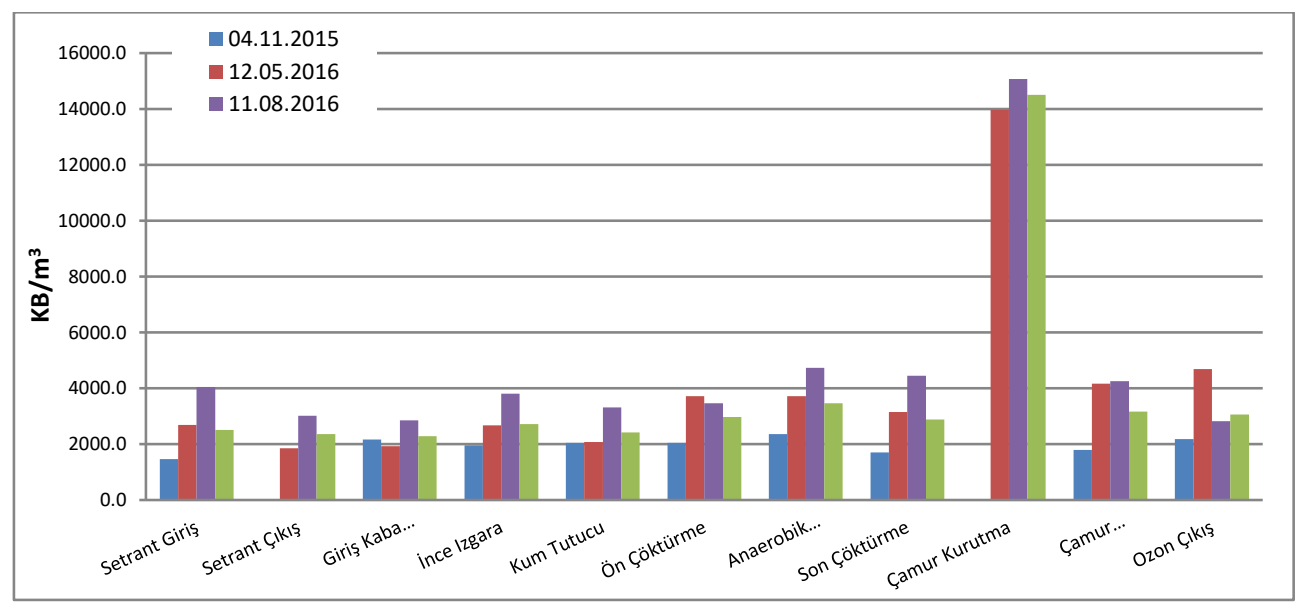

Şekil 3. Olfaktometrik ölçüm sonuçları 


\section{Bulgular}

Üç farklı mevsimde yapılan ölçümler arasındaki farklılığın değerlendirildiği ölçüm sonuçlarına göre ön çöktürme havuzu ve ozon (koku giderim) ünitesi hariç diğer ünitelere ait Ağustos ayı sonuçları en yüksek değerlerdedir. Giriş yapısi/kaba ızgara (terfi merkezi) hariç diğer ünitelere ait Kasım ayı sonuçları en düşük değerlerdedir. Ünite bazında ortalama en yüksek değer çamur kurutma $\left(14.508,5 \mathrm{~KB} / \mathrm{m}^{3}\right)$ ünitesinden elde edilirken ortalama en düşük değer ise giriş/kaba izgara $\left(2.281,3 \mathrm{~KB} / \mathrm{m}^{3}\right)$ ünitesine ait olup Şekil 3'te olfaktometrik ölçüm sonuçları gösterilmiştir.

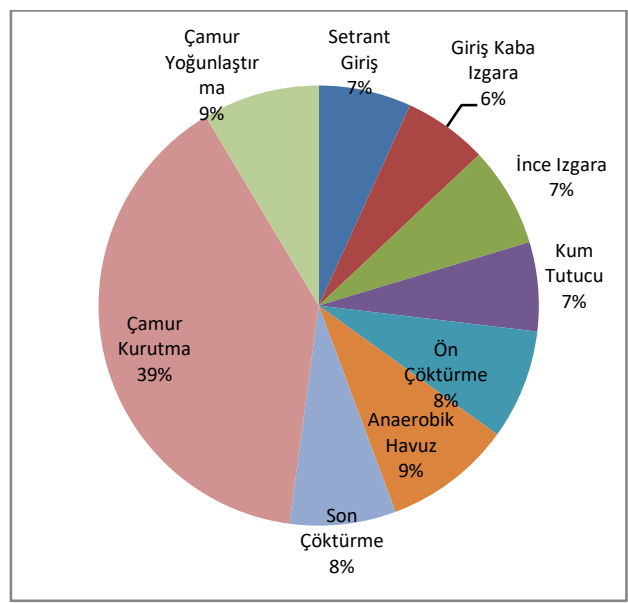

Şekil 4. Tesis ünitelerinin ortalama olfaktometrik ölçüm sonuçlarına göre kokuya katkı oranı

Arıtma tesisleri bütün olarak faaliyet gösteren birbirine bağlı birçok üniteden oluşan bir sistemdir. Bu nedenle tesis kaynaklı koku kirliliği aslında tüm ünitelerin ayrı ayrı meydana getirdiği kirliliğin toplamını ifade etmektedir. Bu nedenle tesiste ünite bazında yapılan değerlendirmede en yüksek koku oluşumu sırasıyla çamur kurutma (\%39), çamur yoğunlaştırma (\%9), anaerobik havuz (\%9), ön çöktürme (\%8), son çöktürme (\%8), ince ızgara (\%7), kum tutma (\%7), setrant (\%7) ve giriș-kaba Izgara (\%6) ünitelerinde tespit edilmiştir. Şekil 4 ortalama olfaktometrik ölçüm sonuçlarına göre tesis ünitelerinin kokuya katkı oranını göstermektedir. Tesis, atıksu ve çamur üniteleri olmak üzere iki ana grupta incelendiğinde atıksu bölümü toplam koku üretiminin $\% 52$ 'ünü, çamur bölümü ise $\% 48$ 'sini meydana getirdiği görülmektedir.

Şekil 5'te bu çalışmada yapılan olfaktometrik ölçümler, çalışan algısına yönelik anket değerlendirmeleri ve Frechen tarafından (1988) yine çalışan algısına yönelik anket değerlendirmeleri gösterilmektedir. Her üç çalış̧mada da çamur kurutma ünitesinin koku oluşumuna en yüksek katkıyı sağladığı görülmektedir. Anketler ile yapılan değerlendirme tesis çalışanlarına ait sübjektif bir yaklaşım olmasına rağmen her iki anket sonucu çamur kurutma ünitesinin ana koku kaynağı olduğu genel kanısını ve olfaktometrik ölçümlerle elde edilen çamur kurutma ünitesine ait sonuçları desteler niteliktedir. Frechen tarafından yapılan ankette çamur kurutmadan sonra çamur yoğunlaştırma, kum tutucu ve ön çöktürme üniteleri diğerlerine göre daha fazla koku oluşumunu sağladığı algısı görülmektedir. Olfaktometrik ölçümlerde ise çamur kurutma ünitesi hariç diğer ünitelerin koku konsantrasyonu genel olarak \%6 ile \%9 arasında çok farklılık göstermeden değişmektedir. $\mathrm{Bu}$ çalışmada yapılan ankette havuzlardan kaynaklı koku oluşumunun en alt seviyede olduğu görülmektedir. Ayrıca çamur yoğunlaştırma ve setrant üniteleri kapalı sistem çalıştı̆̆ için çalışanların doğrudan koku ile temasları olmadığından dolayı çalışanların koku algısı da buna bağlı olarak en alt seviyede kaldığı söylenebilir. Bunun yanı sıra Şekil 5 'de görüldüğü gibi ilk üç ünitede koku algısı ölçümlere göre yüksektir. Girişkaba izgara, ince izgara ve kum tutma üniteleri açık sistem çalışmaktadır. 


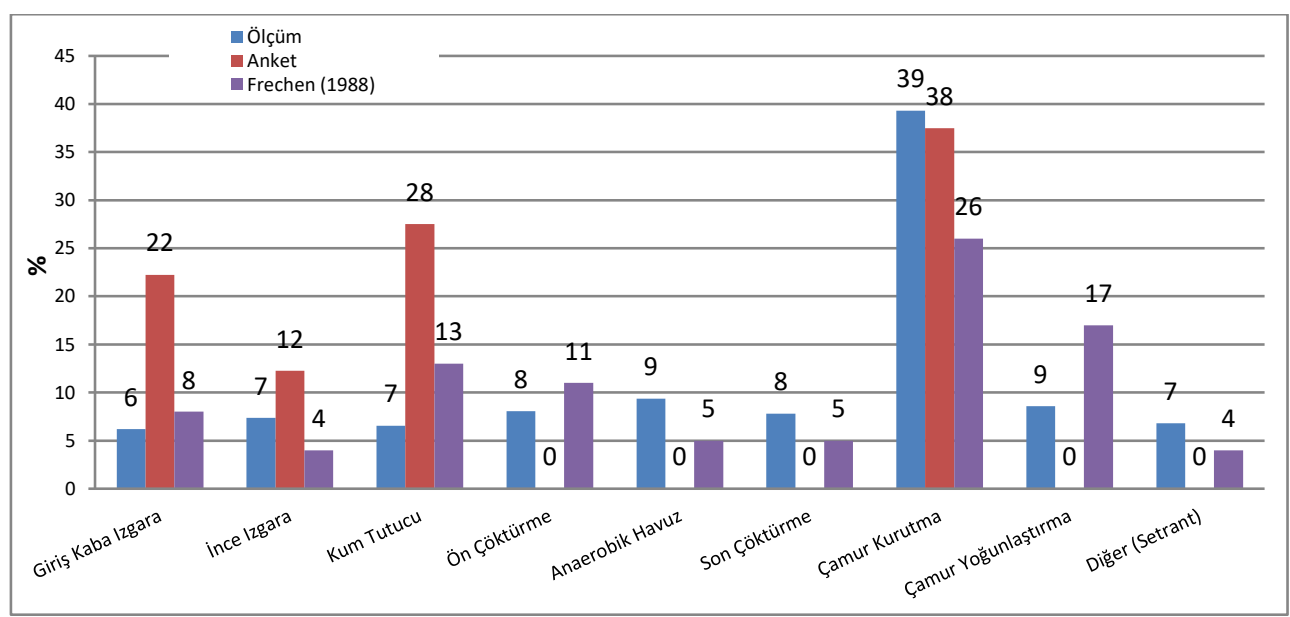

Şekil 5.Tesis ünitelerinin koku oluşumuna katkıları (\%)

Açık sistem çalıştığı için bu ünitelerde oluşan koku doğrudan atmosfer ile temas halindedir. Atmosfer ile temasinı önlemek ve kokuyu kontrol altına almak için bu ünitelerin etrafı kapalı hale getirilerek kokunun yayılımı önlenmiştir. $\mathrm{Bu}$ kapalı ortamda çalışanlar ise daha fazla kokuyu hissettikleri için koku algısı ölçüm sonuçlarına göre daha yüksek çıktı̆̆ söylenebilir.

Çamur kurutma ünitesinde değerlerin yüksek çıkmasına rağmen ozon ile yapılan koku giderim işleminde ozon ünitesine giren toplam koku konsantrasyonları ile ozon ünitesi çıkış konsantrasyonları arasındaki ortalama fark dikkate alındığında \% 84,9 oranında bir koku giderimin gerçekleştiği söylenebilir. Ultraviyole ile yapılan koku giderimi işleminde setrant giriş ve çıkış değerleri arasındaki ortalama fark gözönüne alındığında \% 28,2 oranında bir koku gideriminden bahsetmek mümkündür.

\section{Tartışma ve Sonuç}

Kokuyu oluşturan bileşiklerin türleri ve konsantrasyonlarının tespit edildiği analitik yöntemlerin yanında olfaktometrik yöntem ile insan duyusu yardımıyla yapılan ölçümler koku konsantrasyonunu belirlemede kullanılır.
Koku algısının sübjektif olması, ölçüm için çok zaman gerekmesi ve nispeten yüksek maliyetli oluşu olfaktometrik ölçüm tekniğinin dezavantajları arasında yer alabilir. Özellikle ülkemizde ofaktometrik ölçüme dayalı araştırmalar sınırlı olmakla birlikte Avrupa Birliği uyum sürecinde gelişmelere paralel olarak 2010 yılında koku kirliliğine ilişkin önlemlerin yasal dayanağını olușturan yönetmelik hazırlanmıștır. Böylece olfaktometrik ölçüm metodu yasal bir gereklilik halini almıştır.

Atıksu arıtma tesisleri her bir ünitesinde ayrı bir arıtma prosesinin uygulandığı ve birbirine bağlı kompleks bir teknolojik sistem olduğu için ünite bazında yapılan inceleme tesisin tümünün değerlendirilmesine katkı sağlayacağından dolayı çok önemlidir. $\mathrm{Bu}$ nedenle çalışmaya konu olan arıtma tesisinde yapılan ölçümler ile tesisin her bir ünitesinin kokuya olan katkısı olfaktometrik yöntem ile belirlenmiştir. Yasal dayanak olarak olfaktometrik ölçüm tekniklerinin çok fazla geçmişe sahip olmayışı ve özellikle bir tesisin hemen hemen tüm ünitelerini kapsayan çalışmaların eksikliği bu konudaki karşılaştırmaları kısıtlı hale getirmiştir. $\mathrm{Bu}$ çalışma ile özellikle bu alandaki eksikliğin giderilmesi hedeflenmiştir. 
Atıksu arıtma tesislerinde en çok kokuya neden olan ünitelerin başında çamur proseslerinin gerçekleştiği üniteler gelmektedir ve bunlar yüksek konsantrasyonda kokulu bileşikleri içermektedir. $\mathrm{Bu}$ bilgilere paralel bir şekilde tesis geneli itibari ile çamur kurutma ünitesinde en fazla kokunun tespit edildiği ve yüzdesel olarak en yüksek koku potansiyeline sahip ünite olduğu bu çalışma ile tespit edilmiştir. Ayrıca Dinçer tarafından yapılan çalışmada tesisin beş ünitesinde ölçümler yapılmış olup çamur bölümün ait koku konsantrasyonları diğer ünitelerden daha yüksek olduğu ve bu çalışmada tespit edilen değere çok yakın olduğu görülmüsstür. Bunun yanı sıra tesis içinde çalışanlara yönelik olarak yapılan anket çalışması da daha önce Frechen tarafından yapılan çalışanların koku algısını ile tesisi içi koku kaynaklarının değerlendirildiği çalışmada olduğu gibi çamur kurutma ünitesinin en yüksek koku potansiyeline sahip ünite olduğu doğrultusunda bir bütünlük sergilemektedir.

Tesise giren atıksuyun doğası gereği giriş-kaba izgara, ince ızgara ve kum tutma ünitelerinde koku hissedilir. Tesise giren atıksuyun karakteristik özellikleri bu ünitelerin koku konsantrasyonlarının diğerlerinden farklı olmasına neden olduğu düşünülebilir. Așırı çamur birikiminin görüldüğü ön çöktürme havuzlarında septik koşulların oluşmasıyla koku problemi diğerlerine göre daha fazla olabilir. Ayrıca ünitelerin kokuya yüzdesel katkılarının değerlendirildiği bu çalışmada bu ünitelere ait değerlerin birbirine yakın olduğu görülmektedir. Anaerobik havuzda biyolojik olarak bir arıtım söz konusu olduğundan dolayı koku değeri diğerlerine göre daha fazla iken son çöktürme havuzlarında bu değerin nispeten daha düşük olduğu görülmüştür. Çamur kurutma ve çamur yoğunlaştırma üniteleri ise anaerobik çürütme prosesinden gelen çamur yüksek konsantrasyonda kokulu bileşikler içerdiği için çok daha yüksek değerde kokuya olan katkısı tespit edilmiştir.

KOEKHY'nin 9. Maddesinde şikâyete konu olan işletmenin faaliyet gösterdiği zamanlarda koku emisyonuna neden olan kaynak/kaynaklarından ulusal/uluslararası standartlara göre alınan ve işletme/tesisin koku emisyonunu temsil eden en az üç kokulu gaz örneğinin olfaktometrik olarak ölçülmüş koku konsantrasyonlarının geometrik ortalamasına göre değerlendirme yapılması gerektiği belirtilmiștir. Yönetmeliğe göre ölçüm sonuçları $1.000 \mathrm{~KB} / \mathrm{m}^{3}$ üzerinde ise alınan tedbirlerin kontrolü gerekirken $10.000 \mathrm{~KB} / \mathrm{m}^{3}$ üzerinde ise idari yaptırım uygulanır. Yapılan ölçüm sonuçları birinci limit değer olan $1.000 \mathrm{~KB} / \mathrm{m}^{3}$ değerinin üzerinde olup çamur kurutma ünitesi haricinde $1.000-10.000 \mathrm{~KB} / \mathrm{m}^{3}$ değerleri arasında olduğu belirlenmiştir. Çamur kurutma ünitesinde ölçüm sonuçları $10.000 \mathrm{~KB} / \mathrm{m}^{3}$ değerinden yüksek bulunmuştur. Ancak tesiste etkili bir koku önleme sistemi sayesinde atmosfere salınan ozon ünitesi çıkış konsantrasyon değerleri yönetmelikte belirtilen üst limit değerinin altına indirildiği görülmektedir. Bu durumda işletmede ek koku kontrol tedbirlerinin tekrar gözden geçirilerek alınan tedbirlerin etkinliğinin belirlenmesi için kaynaklarda ölçümlerin düzenli olarak yapılmasının uygun olacă̆ı söylenebilir.

\section{Teșekkür}

Bu çalışma Kocaeli Üniversitesi Bilimsel Araştırma Projeleri (BAP) Birimi tarafindan 2015/23 nolu proje kapsamında desteklenmiştir. Çalışmanın yapılmasına izin veren atıksu arıtma tesisi yetkililerine teșekkür ederiz. 


\section{Kaynakça}

[1] Zarra, T., Giuliani. S., Naddeo. V., Belgiorno. V. 2011. Odour Impact Evaluation from Wastewater Treatment Plant. Proceeding of the 12th International Conference on Environmental Science and Technology, 8-10 September, Rhodes, Greece, 2065-2072.

[2] Chan, A.A., Hanæus, J. 2006. Odorous Wastewater Emissions, Vatten, Cilt. 62, s. 227-236.

[3] Kubo, A.,Naddeo, V., Zarra, T., Uchida, N., Higuchi, T., Belgıorno, V. 2015. Odour Measurement in Wastewater Treatment Plant Using both European and Japanese Standardized Methods: Correlation and Comparison Study, Proceedings of the 14th International Conference on Environmental Science and Technology, 3-5 September, Athens, Greece, 01448.

[4] Dincer, F., Muezzinoğlu, A. 2007. Odor Determination at Wastewater Collection Systems: Olfactometry versus H2S Analyses, Clean Journal, Cilt. 35, s. $565-570$.

[5] Lewkowska, P., Cieślik, B., Dymerski, T., Konieczka, P., Namieśnik, J. 2016. Characteristics of Odors Emitted from Municipal Wastewater Treatment Plantand Methods for Their Identification and Deodorization Techniques, Environmental Research, Cilt. 151, s. 573-586.

[6] Thomas, D.S. 2007. Reducing Hydrogen Sulfide (H2S) Concentrations at Wastewater Collection Systems and Treatment Facilities Using Chemical Oxidation. Florida State University, Department of Civil and Environmental Engineering, Master Thesis, 62 s, Florida.
[7] Vidal, B.V., Nadimi, E.S., Ellermann, T., Andersen, H.V., Løfstrøm, P. 2012. Perceived Annoyance from Environmental Odors and Association with Atmospheric Ammonia Levels in Non-Urban Residential Communities: A CrossSectional Study, Environmental Health, s. 11-27.

[8] Dinçer, F., Odabaşi, M., Muezzinoğlu, A. 2007. Chemical Characterization of Odorous Gases at a Landfill Site by Gas Chromatography-Mass Spectrometry, Journal of Chromatography A, Cilt. 1122 s. 222-229.

[9] Giungato, P., Gennaro, G., Barbieri, P., Briguglio, S., Amodio, M., Gennaro, L., Lasigna, F. 2016. Improving Recognition of Odors in a Waste Management Plantby Using Electronic Noses with Different Technologies, Gas Chromatography Mass Spectrometry/Olfactometry and Dynamic Olfactometry, Journal of Cleaner Production, Cilt. 133, s. 1395-1402.

[10] Gostelow, P.,Parsons, S.A. 2000. Sewage treatment works odour measurement; Water Science of Technology, Cilt. 41,s. 33-40.

[11] Kokuya Oluşturan Emisyonların Kontrolü Hakkında Yönetmelik, 19.07.2013 tarihli v 28712 sayılı Resmi Gazete.

[12] Lebrero, R., Bouchy, L., Stuetz, R., Munoz, R. 2011. Odor Assessment and Management in Wastewater Treatment Plants: a Review, Critical Reviews in Environmental Science and Technology, Cilt. 41(10), s. 915950.

[13] Lasaridi, K., Katsabanis, G., Kyriacou, A., Maggos, T., Manios, T., Fountoulakis, M., Kalogerakis, N., Karageorgos, P., Stentiford, E.I. 2010. Assessing Odor Nuisance 
from Wastewater Treatment and Composting Facilities in Greece, Water Management \& Research, Cilt. 28, s. 977-984.

[14] Zarra, T., Naddeo, V., Belgiorno, V., Reiser, M. 2008. Odour Monitoring of Small Wastewater Treatment Plant Located in Sensitive Environment, Water Science \& Techology, Cilt. 58, s. 89-94.

[15] Shao, L.M., Zhang, C.Y., Wu, D., Lü, F., Li, T.S., He, P.J. 2014. Effects of Bulking Agent Addition on Odorous Compounds Emissions During Composting of OFMSW, Waste Management, Cilt. 34, s. 1381-1390.

[16] Metcalf \& Eddy, Inc. 2003 Wastewater Engineering: Treatment, and Reuse, 4th edition, McGrawHill, Inc., New York, NY, $1848 \mathrm{~s}$.

[17] Liu, H., Luo, G.Q., Hu, H.Y., Zhang, Q., Yang, J.K., Yao, H. 2012. Emission Characteristics of Nitrogen and Sulfur Containing Odorous Compounds During Different Sewage Sludge Chemical Conditioning Processes, Journal of Hazardous Materials, Cilt. 15, s.298306.

[18] Ölmez, S.S. 2008. Odour Control in Wastewater Treatment Plants Using Ozonation and Chemical Scrubbing. Marmara University, Institute for Graduate Studies in Pure and Applied Sciences, Master Thesis, 83 $\mathrm{s}$, İstanbul.

[19] Alp, K. 2013. Atıksu Aritma Tesislerinde Koku Kontrolü. ss 350379. Koyuncu, İ., Öztürk, İ., Aydın, F.A., Alp, K., Arıkan, O.A., İnsel, G.H., Altınbaş, M., Özüdoğru A. Atıksu Sistemleri Tasarım Rehberi, 2013. T.C. Orman ve Su İşleri Bakanlığ $\mathrm{Su}$ Yönetimi Genel Müdürlüğü, Ankara, 427s.
[20] DIN EN 13725. 2003. Air QualityDetermination of Odour Concentration by Dynamic Olfactometry.

[21] Code of Practice on Odour Nuisance from Sewage Treatment Works. 2006. Department for Environment Food \& Rural Affairs UK.

[22] TS EN 12255-9. 2002. Atık Su Arıtım Tesisleri-Bölüm 9: Koku Kontrolü ve Havalandırma.

[23] Zhou, Y., Hallis, S.A., Vitko, T., Suffet, I.H. 2016. Identification, Quantification and Treatment of Fecal Odors Released into the Air at Two Wastewater Treatment Plants, Journal of Environmental Management, Cilt. 180, s. 257-263.

[24] Nicell, J.A. 2009. Assessment and regulation of odour impacts, Atmospheric Environment, Cilt. 43, s. 196-206.

[25] Güvener, H.M. 2004. Investigation of Odorous Emissions And Immissions in Ankara with Olfactometer, Middle East Technical University, The Graduate School of Natural and Applied Sciences, Master Thesis, 134 s, Ankara.

[26] Schiffman, S.S, Walker, J.M.,Dalton, P., Lorig, T.S., Raymer, J.H., Shusterman, D., Williams, M. 2008. Potential Health Effects of Odor from Animal Operations, Wastewater Treatment and Recycling of Byproducts, Journal of Agromedicine, ISSN: 1059-924.

[27] Vantarakis, A., Paparrodopoulos, S., Kokkinos, P., Vantarakis, G., Fragou, K., Detorakis, I. 2016. Impact on the Quality of Life When Living Close to a Municipal Wastewater Treatment Plant, Journal of Environmental and Public Health, DOI: $10.1155 /$ s8467023. 
[28] Winneke, G. 2004. The Assessment of the Impact of Environmental Odours in the Community. Environmental Odour Management International Conference, 17-19 November, Cologne, Germany, 9-12.

[29] Akmırza, İ. 2012. Gıda Endüstrisi Kaynaklı Koku Emisyonlarının Kontrol Stratejilerinin Geliştirilmesi, İstanbul Teknik Üniversitesi, Fen Bilimleri Enstitüsü, Yüksek Lisans Tezi, 77 s, İstanbul.

[30] Atimtay, A.T., Bayram, A., Bilgili, S., Bolcu, E., Demircioğlu, H., Dinçer, F., Fisher K., Güvener, M., Homans, W.J., Müzeyyenoğlu, A., Şahin, M. Sanalan, T., Tok, E. 2004. Odour Emissions and Immissions Management Policy in Turkey: A National Initiative. Environmental Odour Management International Conference, 17-19 November, Cologne, Germany, 61-69.

[31] Dinçer, F. 2007. Characteristics and Chemistry of Odors from Selected Industrial Facilities in İzmir, Dokuz Eylül University, Graduate School of Natural and Applied Science, Master Thesis, $151 \mathrm{~s}$,İzmir.

[32] Niu, G.Z., Xu, S.Y., Gong, Q.C. 2014. Health Risk Assessment of Odors Emitted from Urban Wastewater Pump Stations in Tianjin, China, Environmental Science and Pollution Research, Cilt. 21, s. 10349-10360, DOI 10.1007/s11356-014-2984-7.

[33] Frechen F.B. 1988. Odour Emissions and Odour Control at Wastewater Treatment Plants in West Germany, Water Science of Technology, Cilt. 20, s. 261-266.

[34] Fang, J.J., Yang, N., Cen, D.Y., Shao, L.M., He, P.J. 2012. Odor Compounds from Different Sources of Landfill: Characterization and Source
Identification, Waste Management, Cilt. 32, s. 1401-1410.

[35] Aatamila, M.,Verkasalo, P.K., Korhonen, M.J., Viluksela, M.K., Pasanen, K., Tiittanen, P., Nevalainen, A. 2010. Odor Annoyance near Waste Treatment Centers: A Population-BasedStudy in Finland, Journal of theAir\&Waste Management Association, Cilt. 60 s. 412-418. 